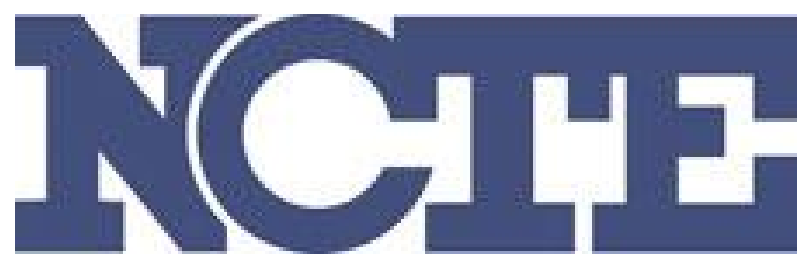

On Going Home: Selfhood in Composition Author(s): Evan Carton

Source: College English, Vol. 45, No. 4 (Apr., 1983), pp. 340-347

Published by: National Council of Teachers of English

Stable URL: http://www.jstor.org/stable/376542

Accessed: 09-08-2016 16:57 UTC

Your use of the JSTOR archive indicates your acceptance of the Terms \& Conditions of Use, available at

http://about.jstor.org/terms

JSTOR is a not-for-profit service that helps scholars, researchers, and students discover, use, and build upon a wide range of content in a trusted digital archive. We use information technology and tools to increase productivity and facilitate new forms of scholarship. For more information about JSTOR, please contact support@jstor.org.

National Council of Teachers of English is collaborating with JSTOR to digitize, preserve and extend access to College English 


\section{On Going Home: Selfhood in Composition}

Whatever their organizational or methodological differences, contemporary composition rhetorics typically begin with a "personal appeal." In clear and forceful prose, softened by accents of reason and sympathy, they rehearse the evident values and benefits of good writing - values and benefits, they intimate, that the student, however inarticulately, recognizes and cherishes. Their concerns, the texts assert, are and ought to be the student's own. (That the instructor wholeheartedly shares them is simply assumed.) The composition topics they suggest-college life, devil worship, the generation gap, solar energy, television, feminism, fashion, collective bargaining-exuberantly press their claim. Good writing, the student is told, requires above all else the choice of a subject that the writer knows and cares about. "The place to begin obviously is with your own personal experiences, your thoughts, feelings, and observations," Frank D'Angelo advises; ${ }^{1}$ and we, steeped in the powerful truth of this commonplace for so many literary masters, echo it as our students tailor their thoughts, feelings, and observations to the various modes and aims of composition. Anomalously, the fruits of such profuse attention to selfhood are often trite, detached, and interchangeable essays that arouse in us, along with a sense of failure, the eerie, guilty, desperate, and hastily banished thought: "These students have no selves to express."'

We banish the thought for several reasons: because it smacks of a defensive and cynical elitism that we neither admire nor accept; because its implications for our own sense of professional identity and purpose are frightening; because, in what my colleague Gayatri Spivak has called "our unwitting complicity with a world that efficiently marginalizes us, ${ }^{2}$ we question our right to make such a judgment and mistrust the values upon which it would have to rest. It is easier, although no less painful, to take ourselves and our students off the hook by

1. Process and Thought in Composition, 2nd edition (Cambridge, Mass.: Winthrop, 1980) p. 7. I cite D'Angelo's text in this essay as a representative rather than a particularly offensive one.

2. "Reading the World: Literary Studies in the 80s," College English, 43 (1981), 672.

Evan Carton is an assistant professor of English at the University of Texas at Austin. He has published essays in American literature, romanticism, and on Chaucer and currently is completing a book, Parodies of Possibility: The Rhetoric of American Romance.

College English, Volume 45, Number 4, April 1983 
defining our engagement in composition classes as "pragmatic" or "functional," thereby withholding (and degrading) the intellectual, moral, and ideological commitment that most of us bring to the teaching of literature. It is easier, although highly ironic in light of the personalizing efforts of the texts we use, to dismiss the issue of selfhood and simply concentrate on establishing a minimum standard of writing competence. The inadequacies of our students' performances, after all, need hardly be attributed to lack of selfhood. Inattention to instructions, insufficient effort, anxiety, immaturity, and poor high school preparation present themselves as more sensible explanations. Embracing these "value-free", explanations, however, we ignore or deny the primary obligation of any writer or teacher of writing to establish the sense of personal relationship to his or her enterprise that alone confers upon it form, substance, and value. Consequently, we can offer detailed suggestions for improvement but only one general incentive, one that many of us disrespect and most of us disbelieve. Our textbooks may put it subtly or thus baldly: "Even in an electronic age, you can scarcely hope to succeed unless you can express yourself in writing with some degree of effectiveness"' (D'Angelo, p. 4).

Such generalizations may effectively obviate the identities of teachers and students, but they in no way preempt or neutralize the issue of selfhood. The universal "you" who can scarcely hope to succeed without self-expression is the one-of-a-kind "you" who must express personal thoughts, feelings, and observations. The composition textbook "you," in short, however sincerely and inoffensively meant, is the distinctively uniform, mass-produced unique of Madison Avenue campaigns. Epitomized in the slogan of America's most successful fast food chain, this is the "you" who deserves a break today, a consumer rather than a producer of his own image who must, in the logic of McDonalds' shrewd appeal, redeem his individuality by joining the crowd. The advertiser's personal rhetoric masks a cynical contempt for the value of selfhood; the identical rhetoric of the composition text or teacher more often masks a genuine though unconfessed despair of students who are autonomous in mind and motive. The irony of this universal you pervades and conflates public and private expression in America. It is this irony, in fact, that Christopher Lasch identifies and elaborates as the dominant feature of our society in The Culture of Narcissism (New York: Warner Books, 1979). Against the popular analysis and media cliché of "the Me generation," Lasch bravely and convincingly argues: "It is the devastation of personal life, not the retreat into privatism, that needs to be criticized and condemned"' (p. 64).

The standard composition class, based on an appealingly rationalized and packaged program of rhetorical principles and methods, complies with this devastation-unwittingly, perhaps, but not innocently or ineffectually. For the trivialization of selfhood in composition texts and the suspension of any rigorous ideal of selfhood by writing teachers do not render invalid or inconsequential their assumptions about the attitudes and aims of students. What condemns the composition class (and us), on the contrary, is the accuracy with which so many students are characterized and the faithfulness with which "their interests" are served by the class. Here lies our complicity, and its significance is hardly mar- 
ginal. We are, or ought to be, condemned to acknowledge that our activities as composition teachers are not "pragmatic," in the eviscerated usage of the term to mean disinterested, value-neutral, apolitical. Rather they are inescapably ideological. We cannot choose to dismiss the issue of selfhood. We can only try to choose the kind of personal identity we wish to recognize and encourage in our students, the kind of interests we wish to serve, the kind of value we wish to represent. We can either struggle to produce our own image of success or struggle to consume an indigestible one.

The divorce of writing from reading, of literacy from literature, in the composition course represents a choice that I find unacceptable. It is a choice to eviscerate the purposes and methods (or "aims" and "modes") of writing by abstracting them from the engagement with human situations that alone gives them substance and meaning. The classroom, after all, provides a context that cannot accommodate the fulfillment of most of the purposes that are expected to shape and motivate the student's expression. Without a genuine situation to define or goal to sustain it, the notion of purpose itself is trivialized, the student is alienated from his or her own expression, and the course, failing to offer a model of academic stature and value, becomes not practical but "academic" in the pejorative sense of the word. Personal purpose is undermined, too, by the definition and prescription of available purposes in the rhetorical syllabus. By presenting writing as a tool that may be adapted to various discrete jobs, the rhetorical approach implies that purposes are not enacted and discovered in experience but selected from a finite, objective, and institutionally authorized set. This objectification of purpose is reinforced by the noncontextual emphasis on information-an emphasis in which the composition course, dependent for writing topics upon an arbitrary and attenuated topicality, imitates the mass media. Detached from history and from the need for contextual explanation or justification, independent of responsible authorship, information dehumanizes. That students encounter it and believe they are expected to accept it in this guise is evident in their essays. When they write for us in composition courses, they depersonalize the most personal areas of experience and persistently consider the writer's task to be the articulation of the most unobjectionable and widely recognized "truths." Under these circumstances writing is a form of consumption.

Paradoxically, it is reading rather than writing that better exercises, develops, and expresses the self. Where writing often codifies identity for the college student (usually prompting him or her to embrace the most readily available social, rhetorical, and ideological codes), reading challenges identity by the very otherness of the text and the initial indeterminacy of its relation to the self. In a society that has come to see the public world as a mirror of the self (thus ensuring that the self will mirror the public world), the emotionally, conceptually, or stylistically subtle text can shatter both images and force revision. ${ }^{3}$ I recognize that, in making this claim, I seem to idealize reading at the expense of writing. But my intention is to collapse this false opposition by insisting that good writing

3. Lasch makes this observation, acknowledging Richard Sennett's The Fall of Public Man as an influential source, on p. 66 of The Culture of Narcissism. 
is always and only the tangible fruit of sensitive and habitual reading; it is the responsive adaptation to a particular occasion of one's power to "read" one's language and oneself. If, as I believe, students write poorly because they lack this power or insufficiently recognize and value it, and if most writing texts and curricula ignore, disguise, or sanction this insufficiency, then one must look to reading not to preempt but to facilitate composition.

Because it is not a convenient item of consumption, the text requires selfconscious engagement of its reader. Because it does not claim to possess absolute immediacy and unconditional relevance, it demands that its reader shape the context in which he or she may desire and comprehend it. Reading, then, confronts the student more compellingly than writing does with an opportunity to forge the conscious dialectical engagement with the world upon which selfhood and effective self-expression depend. Psychoanalysis has demonstrated that children who fail to experience or accept opposition from without often. lack a strong sense of identity. In The Culture of Narcissism Lasch depicts a society that has hidden all traditional forms of authority behind a deceptive rhetoric and ideology of cooperation and therapy-a society that quietly cripples not the expression of division but its perception. The merely rhetorical approach to composition, in its cooperative and therapeutic attitude toward students and their writing, does not provide the constructive opposition that might stimulate the rise of the individual's best self and thwart the rise of America's worst.

I have struggled to define my apprehensions about composition for several years now, but the experience that helped me link and subordinate them to the issue of selfhood occurred only recently. About a month into the semester, in a better than average freshman class, I asked my students to read Joan Didion's essay "On Going Home" and assigned a composition on it. "On Going Home" appears both in Norton's composition reader and in Little Brown's; its attractiveness for such anthologies doubtless lies in its brevity, contemporaneity, and personal subject-a young woman's feelings about the extended family of her childhood, the nuclear family of her adulthood, and herself. In the introductory paragraph of my assignment, I noted that Didion's attitudes toward her two families and toward "home" itself were complex and that nowhere in her essay was there a simply stated thesis. My students' challenge then, I instructed, would be to explain Didion's response to her personal situation, to formulate their own statements of the meaning of her essay, by piecing together the comments, images, and descriptive details that they thought were most revealing and representative. We briefly discussed the essay and the assignment before the students went home to reread and write. Of the twenty-two compositions I received, however, not one conveyed a significant comprehension of "On Going Home." Perplexed, annoyed, and vaguely guilt-ridden, I returned to class and told the students that, despite Didion's vivid reflections, observations, and images, in their own essays they had scarcely attempted to delineate her character or the nature of her relationship to her family. I reiterated that they could only understand "On Going Home" through a close examination of that character and that relationship as expressed in Didion's language, and I suggested specific 
questions and passages that I hoped would facilitate such an examination. Promising to disregard the first set of grades (mostly D's) but to record the next, I gave an inspirational halftime speech and challenged them to start afresh and show me their best effort. There was no appreciable difference between the second group of compositions and the first.

Mutually frustrated, my students and I reviewed the essay and the problems they had had with it, forgave each other our trespasses, and went on. Brooding intermittently for weeks over the oddly uniform poverty of their performance, the nature of Didion's essay, and my sense of some significant connection between the two, I eventually arrived at a "reading" of the incident. I neither did nor would directly present this argument to my freshman class, but if it is valid I think it must inform our choice of texts, our construction of syllabuses, and the fundamental conception of our enterprise in freshman composition. My students' failure, I believe, had little to do with poor writing skills. Nor was it simply a matter of their immaturity or incapacity as readers, although the cause of their trouble with this assignment does figure generally in the difficulty that many students experience when asked to read reflectively. Primarily, they failed because Didion's personal meditation presented them with a model of engaged and reflective selfhood that they did not share and could only recognize, if at all, as a vaguely threatening, duplicitous, and disturbed presence.

The narrator of "On Going Home"' is a young woman who is struggling to understand and articulate her ambivalent feelings toward both her past and her present. These realms represent not merely aspects of her life but aspects of herself; she feels her identity invested in both, and she notes her use of the word "home" to mean not "the house in Los Angeles where my husband and I and the baby live" but "the place where my family is, in the Central Valley of California." During a visit "home", on the occasion of her daughter's first birthday, Didion is overwhelmed by the emotional weight and associative richness of familiar objects and oblique, ritual exchanges with her parents and her brother. She knows that her husband, who values clarity in conversation and neatness in a house, finds little meaning in such resonances. And although almost hypnotically attracted by the apparent venerability and rootedness of a past that provides a vivid contrast to her glib and mobile modern life, she herself recognizes that these characteristics are partly illusory and partly undesirable as well. The impression of wisdom often masks mere inscrutability; the sense of stability hardens ominously into the fact of torpor or shatters into brittle fragments. The scattered pieces of the past offer Didion no master key to the present or even to themselves. "There is no final solution for letters of rejection from The Nation and teacups hand-painted in 1900 . Nor is there any answer to snapshots of one's grandfather as a young man on skis, surveying around Donner Pass in the year 1910. I smooth out the snapshot and look into his face, and do and do not see my own." There is little overt contact between Didion and her family during her visit, and yet its description evidences the paradoxical intensity of emotion that she earlier remarks upon: "I had by all accounts a 'normal' and 'happy' family situation, and yet I was almost thirty years old before I could talk to my family on the telephone without crying after I had hung up. We did not fight. Nothing 
was wrong. And yet some nameless anxiety colored the emotional charges between me and the place that I came from." Her daughter, Didion realizes, will not have to "carry the burden of "home", long into adulthood, and "perhaps it is just as well." Still, Didion "would like to give her home for her birthday" but "can promise her nothing like that," since "we live differently now" and since she herself no longer securely has it to give.

Despite the fact that solitary meditation predominates in Didion's visit and in her account, most of my students did not see that "On Going Home" is about Didion, that her principal subject is herself. Instead, they found ways to deflect the focus of the essay or to externalize its conflict. Some latched onto the husband, mentioned once after the opening paragraph, and argued that "On Going Home" was the story of his successful or unsuccessful effort to win the undivided allegiance of his recalcitrant wife. A few took up the infant daughter, characterized only in the last paragraph, and debated the value of the home life her mother was likely to provide for her. Many obviated the issue of selfhood by dissolving Didion's tensions and ambivalences and recasting them as hypostatized images of popular cultural attitudes. To them the essay presented the problem of choosing between a slow-paced rural life and a fast-paced urban one; the essay contrasted the "happiness" and "innocence" of childhood with "the emergence of adult responsibility"; the essay depicted the yawning abyss of the generation gap for one who "believes" in old-fashioned values yet is "a representative of the new generation."

The common element in these interpretations is the need to objectify and standardize in order to approach the internal and the personal. Following the lead of pop psychologists, the mass media, and the literature of self-help, my students understood the problem of identity only in terms of the static accessibility of alternative self-images; the dynamic and dialectical productivity of selfconsciousness was unavailable to them. Instead of accepting the complexity of Didion's feelings and impulses, they demanded that she resolve and effectively deny this complexity by choosing a course of action. Moreover, they read the essay, however insistent its contrary refrain ("There is no final solution"; "nor is there any answer"; "Questions trail off, answers are abandoned"), as if it authorized this demand. Didion must decide between the present and the past, between conventional "beliefs," between the fitted and equally unfit images of identity that her parents and her husband prepare for her. She must, my students felt, face the same facts that everyone else must face, and by "facts" they seemed to mean predetermined and immutable categories of experience and value. Again and again their compositions advanced an unexamined notion of universality as the sole standard of validity and revealed their assumption that analysis itself could and should only be an exercise in universalization. Ultimately, Didion is no different from anybody else. "Memories we all have, memories of the good old days."

Those students who did not ignore or neutralize Didion's personal identity repudiated it. They accused her of "immaturity" or contended that "her priorities are undeveloped in the sense that she tries to maintain two lives." "To me it seems strange," wrote one student, "that a grown woman cannot adapt to 
the concept of ... having a home and life of her own away from her family" (my emphasis). Another accused Didion of "regressive" behavior and argued that, having already betrayed her family, husband, and child, she finally "betray(s) herself by refraining from evolving." Didion fails because "she refuses to stick to her own life pattern and chooses rather to adapt to those around her," one composition concluded. An equally suggestive summary statement was this: "I feel that when a person gets married, a new home should be formed with nothing around to take its place in importance."

Doubtless these attitudes are partly attributable to the natural anxieties that attend the adolescent's demand for autonomy and adult status, but I think it would be a mistake to discount their seriousness or dismiss their social implications on this basis. It is significantly ironic, for instance, that the failure of Didion's accusers to recognize her selfhood took the form of a complaint that she lacked a mature identity. Disturbingly, their idea of a mature identity seemed a rigid and desolate abstraction. In the revealing paradox articulated by a student whom I quoted twice above, maturity is the refusal to "adapt" to people and circumstances and the willing ability to "adapt" to an externally imposed "concept" of maturity, to a conventionally authorized "life pattern." The term "pattern," too, suggestively opposes a spatial organization of identity to the various models by which my students ostensibly acknowledged, but actually obscured, the temporal dimension of selfhood. Maturation, development, adaptation, and evolution were employed blithely and (I might histrionically add) in all historical innocence as clubs to beat Didion down or knock her into line. In so using them my students took these ideas to signify not complex and integrated processes but fixed hierarchies of achievement. Thus the biological and psychological fact that informs each term-the fact that identity is at once constant and constantly changing, that selfhood is only sustained in reciprocal engagement with one's environment and one's past-was precisely what they missed or rejected. Because they lacked an appreciation of temporality, my students could neither accept the self's dependence upon a history nor recognize its power to integrate and surmount its history. For them the self must avoid the obliquity of context and, like a board-game token, receive completely new instructions at each square.

Didion's essay offers an opportunity that the assignment invited my class to take up: the opportunity to recognize the complexities and relativities of human experience, to accept the challenge of self-conscious engagement in one's own life and in the lives of others. The responses disturbed me not because they failed to yield a particular judgment of Didion that I had predetermined to be correct but because they indicated an inability or unwillingness to accept Didion's challenge. Perhaps the students declined this engagement not out of incapacity or indifference but because they found it obstructive rather than intrinsic to good writing. In either event the practice of written self-expression for them seemed to exclude, even to oppose, the activity of self-conscious questioning.

The possibilities for selfhood that my freshmen denied, however, are precisely the possibilities that reading allows, nurtures, and celebrates. Foremost among 
these is a meaningful sense of temporality, in the absence of which self and text is each reduced to a still life. The appreciation of one's existence both at a particular moment and in a succession of moments initiates the dialectic of involvement and critical detachment that produces and sustains a personal identity-an active self that recognizes its own contextuality and so must engage its times, but a self that also recognizes the multiplicity of its contexts and so need not be enslaved by them. Self-consciousness and consciousness of the world are mutually determinative and mutually enabling. To my students, though, they seemed mutually exclusive. For some Didion's introspection was no less than a cowardly evasion of the world and-since capitulation to "reality" was their measure of mature identity - a self-betrayal as well. "In childish haste to comb deeper into her thoughts," Didion ignores her husband's needs, one detractor noted, while another pronounced: "She turns inward, not looking for answers, but escaping from them." Perhaps the value of literacy, like the value of selfhood, lies in its provision of the resources to resist or escape the sorts of answers that replace and preclude questions.

It has not been my intention here, as some satirical reader might suppose, to lay the groundwork for a proposal that the freshman composition course consist of readings in Henry James' major phase. Rather I have sought to articulate an explanation of our problems and those of our students in the writing class. I think this explanation has been avoided because it implies that these problems exist and it demands that we view them in the contexts of political and economic influence, social psychology, and "subjective" personal values. To argue that the cultural crisis of personal identity is central to the inadequacies of our composition texts, curricula, and students is, I recognize, easier than to propose a program that might combat rather than merely reflect this crisis. I understand too that any program is legitimately constrained by the students' levels of ability and achievement, and that it must somehow recognize the claims of what they perceive to be their needs and of the needs perceived for them by parents, politicians, trustees, employers, and society at large. But when these pressures are solely determinative, the writing course consists of little more than a pastiche of contemporary clichés in its material and in its products. No other serious college course so lacks a coherent subject matter to provide a context for thought and expression. No other so little challenges students to acquire the habit of questioning, revising, and enhancing their notions of who and where they are. A good writer meets this challenge. Critical reading-whether in Shakespeare, the philosophy of science, the application of supply side economics, or the history of the Roman Empire-intrinsically poses it; rhetorical models and exercises do not. Our writing classes are not likely to fulfill their function until they reorganize themselves around coherent and sustained programs of reading. When we restore the relationship between reading and writing and between writing and selfhood, students may begin to find the composition course personally meaningful. Even more importantly, through the reciprocal definition and confirmation of their identities and their prose, they may realize the truth that has been obscured in our society and in our classrooms: that selfhood is always in composition. 